Lenzer. I I Differences between behavior reinforced by electrical stimulation of the brain and conventionally reinforced behavior: An associative analysis. Psychological Bulletin. 1972, 78,103-118

Reid. L. D.. Wasden. R. E.. \& Courtney. R. J. Reinforcing limbic system stimulation and sodium amytal. Psychonomic Science. 1970.18,47-48

Reid, I. D.. Hunsicker. J. P.. Kent, E. W.. Lindsey. J. L.. \& Gallistel. C. R. Incidence and magnitude of the "priming effect" in self-stimulating rats. Journal of Comparative \& Physiological Psychology. 1973.82.286-293.
Wasden. R. E.. \& Reid. L. D. Intracranial stimulation: Performance decrements and a fear-reducing drug. Psvchonomic Science, 1968,12,117-118

West G. L Hunsicker. P \& Reid. L. D. Performance differences for intracranial reinforcement as a function of recency and number of stimulations. Communications in Behavioral Biology. 1971.6.171-176.

(Received for fubiication July 20.1973.)

\title{
Habituation of cardiac components of the orienting reflex to stimuli repeated at fixed and variable intervals
}

\author{
EDWARD S. KATKIN and JLDITH S. NELSON \\ State Liniversity of Vew York at Butfalo. Butfalo. . Y. Y. 1t:2h \\ The purpose of this study was to determine the \\ effects of fixed-interval (FI) stimulus repetition on \\ cardiac components of the orienting reflex (OR). It was \\ predicted that variable stimulus repetition would lead to \\ habituation of the OR. whereas a fixed itemporal \\ conditioning, interval paradigm would inhibit such \\ habituation. Thirty-six Ss were employed. The main \\ hypothesis concerning the effects of FI stimulus
}

\begin{abstract}
repetition was confirmed. In addition. the data supported the use of Lang \& Hnatiow's (1962) peak-to-valley measure of the cardiac response, although the response appeared to be monophasically decelerative. not diphasic. The results suggest that stimuli having "signal functions" will continually elicit the OR. whereas stimuli not having such functions eventually lose their value as OR elicitors.
\end{abstract}

Experimeitat studias at heart ate (HR) genera!!!

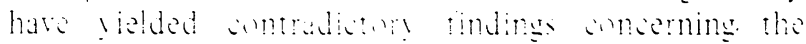


directionality of response. These apparent contradictions were clarified in part by Lang \& Hnatiow (1962). who suggested that the cardiac response is actually diphasic. showing initial acceleration followed by a longer latency deceleration. Thus. Es who measure the response immediately after stimulation should find acceleration. whereas Es who measure it more than 5 sec after stimulation. should find deceleration.

Lang and Hnatiow proposed a "peak-to-valley." measure of HR. Which takes into account both the accelerative and decelerative components of the response. This measure. the fastest of the first 6 beats following stimulus onset minus the slowest of the next 15 beats. was held to be a reliable index of the diphasic cardiac response. To substantiate their point. Lang and Hnatiow exposed $S$ s to repeated stimulation and compared the habituation curve obtained by their peak-to-valley method with habituation curves obtained by other methods of HR measurement. Their assumption. based on both association learning theory and Russian research on the orienting reflex (OR), was that the HR response should show extinction with stimulus repetition. and that the index producing the clearest habituation curves should be the most meaningful index of the cardiac response associated with the OR. As predicted. the peak-to-valley score yielded the most adequate curve of habituation.

Subsequent research by Geer (1964) on the measurement of the conditioned cardiac response supported Lang and Hnatiow's contention that the cardiac response was diphasic and also found that the peak-to-valley score habituated with stimulus repetition. Additionally. Geer demonstrated that, by pairing the repeated stimulus with a shock or noxious tone (UCS). the habituation of the OR to the first tone (CS) could be inhibited. Thus, Geer concluded that the effect of classical conditioning procedures was to inhibit the normally occurring habituation of the HR response to the CS.

On the assumption that the effects of the temporal conditioning paradigm are approximately the same as those of classical conditioning. it might be expected that stimulus repetition at a fixed time interval might also inhibit habituation of the OR to the UCS. Lang and Hnatiow did. in fact, utilize a fixed interval (FI), which thereby established a temporal conditioning paradigm: however, they did not obtain inhibition of habituation. as Geer did.

The purpose of the present experiment was to compare the effects of FI stimulus repetition and variable interval (VI) stimulus repetition on the $H R$ response. On the assumption that the $H R$ response is susceptible to temporal conditioning and that the effects of such conditioning are similar to those of classical conditioning, it was hypothesized that $\mathrm{Ss}$ in the FI condition would not show habituation of the response to a repeated stimulus, whereas Ss in the VI condition would show clear patterns of habituation.

In an attempt to evaluate the form of the response to different levels of stimulation. two stimuli of different intensities were employed. It was predicted that high-intensity stimulation was likely to elicit HR acceleration assciated with what Sokolor (1963) might sall the defense reflex (DR).

\section{METHOD \\ Subjects}

The Si were it undereraduate students 130 female and 6 males enrolled in the introductory pstihology course at the State Lniversity of Vell York at Buffalo.

\section{Apparatus}

The Ss were run in a diml! illuminated soundproof shamber. seated in a comfortable lounge chair. HR was detected from arm to arm by silver electrode and amplified by a Grass Instruments Co. Model SP6 preamplifier. Both HR and respiration were recorded on a Grass Model इ polygraph. Llectrical stimuli were delivered to the finger by a 60 -cyle as stimulator ranging from 0 to $30 \mathrm{~V}$. isolated from ground. The polygraph. amplifiers. and stimulator were all located outside the thamber.

\section{Procedure}

The Ss were assigned randomly to one of four experimental groups: VI. high intensity: VI. low intensity: FI. high intensity: or FI. low intensity.

For the first 7 min. no stimulation was administered. After that. each $S$ received 20 electrical stimuli of 2 sec duration. The $\mathrm{Ss}$ in the two FI conditions received the stimuli at 30 -sec intervals. and $S s$ in the two groups received them at intervals varying around $30 \mathrm{sec}$ in s-sec steps between 10 and $45 \mathrm{sec}$. The high-intensity stimuli were delivered at $30 \mathrm{~V}$ and the low-intensity stimuli were delivered at $18 \mathrm{~V}^{\circ}$

\section{RESULTS}

In order to determine if there were differences among the four experimental groups prior to stimulation. basal HR was evaluated for the last $2 \mathrm{~min}$ of the initial $7-\mathrm{min}$ period. using the smoothed-peak-rate method suggested by Opton. Rankin. \& Lazarus (1965). No initial differences in heart rate were found among the four groups.

The cardiac response to each of the stimuli was evaluated by Lang and Hnatiow's peak-to-valley score. After these scores were obtained for the 20 trials, they were grouped in five trial blocks of four trials each. Analysis of variance of these data indicated no main effect of stimulus intensity and no interactions of stimulus intensity with any other variable, but a significant interaction of ISI with trial blocks ( $\mathrm{F}=\mathbf{2 . 9 9}$. $\mathrm{df}=4 / 128 . \mathrm{p}<.025$ ). confirming the observation that. irrespective of stimulus intensity. the heart-rate response declined across trials for Ss in the VI conditions but not for $\mathrm{Ss}$ in the FI conditions. Postexperimental interview data indicated that the "high-intensity" stimulus was not perceived by Ss as being intense: hence. the failure to obtain stimulus intensity effects may be the result of inadequate stimulus selection.

The significant ISI by Trial Blocks interaction is depicted in Fig. 1. Since further analyses indicated that there was no difference between groups during the initial trial block. the data have been plotted as difference scores between the initial trial block and succeeding 
blocks. Negative sonres indicate habituation. and positive scores indicate facilitation. Inspection of Fig. 1 reveais that reduction of responses to an asimptotic level for $S$ s in the VI group took place between the first and second trial blucks.

Although the present findings substantiate the value of the peak-to-valle! score as an index of the HR response. it is still a moot question whether the results obtained were a result of systematic changes in both the accelerative and decelerative components of the response or in either of them alone. In order to evaluate this further. all peak-to-valley scores were broken down into their component parts. so that for each S. five "slow" scores and five "fast" scores were obtained. one for each trial block. An analysis of variance of "habituation scores" obtained in this manner for Ss in the two ISI groups indicated that differential habituation as a function of ISI was statistically significant only for the total peak-to-valley score, and not for either of its components. Each of the records was scrutinized to determine if the HR response was diphasic in all cases. The results indicated that 24 Ss showed a stable decelerative response. 10 showed an accelerative response. and 2 showed no response. There was no relationship between wave form and stimulus intensity.

On the assumption that the differential effects obtained between Ss in the FI and the VI groups might have been accounted for by a temporally conditioned anticipatory HR response occurring for $\mathrm{Ss}$ in the FI group. the data for the $12 \mathrm{sec}$ immediately preceding each stimulus onset for $\mathrm{Si}$ in both the FI and the VI groups were examined. Both accelerative and decelerative components were scrutinized. and difference scores between the first 6-sec period and the second 6-sec period preceding onset of the stimulus were obtained first for peak heart rates and then for valley. heart rates. Analysis of variance indicated that there were no anticipatory heart-rate changes of an accelerative. decelerative. or biphasic nature for any Ss. irrespective of experimental group.

\section{DISCUSSION}

The main findings of the present study may be summarized as follows. First. repeated $\mathrm{H}$ I stimulation inhibits habituation of the cardiac component of the OR. but has no discernible effect on the anticipatory HR response. Second. in the present study, the $\mathrm{HR}$ response was decelerative for most Ss. accelerative for some. but rarely a stable diphasic response: furthermore. neither the form of the response nor its habituation were related to the two different levels of stimulus intensity employed.

The finding that a fixed-interval paradigm inhibited habituation of the OR. at least as it is reflected in Lang and Hnatiow: peak-to-valley measure of cardiac responding. but did not result in anticipatory $H R$ changes indicative of temporal conditioning is consistent with Gerr's report that the slassical conditioning paradigm resulted in no acquisition of a "new" conditioned response. but did inhibit habituation of the $L(C R$.

Data bearing on the separate accelerative and decelerative components of the response substantiate further the use of the peak-to-valley sore. for no consintent interstoup differences were obtained when either the acolerative or decelerative

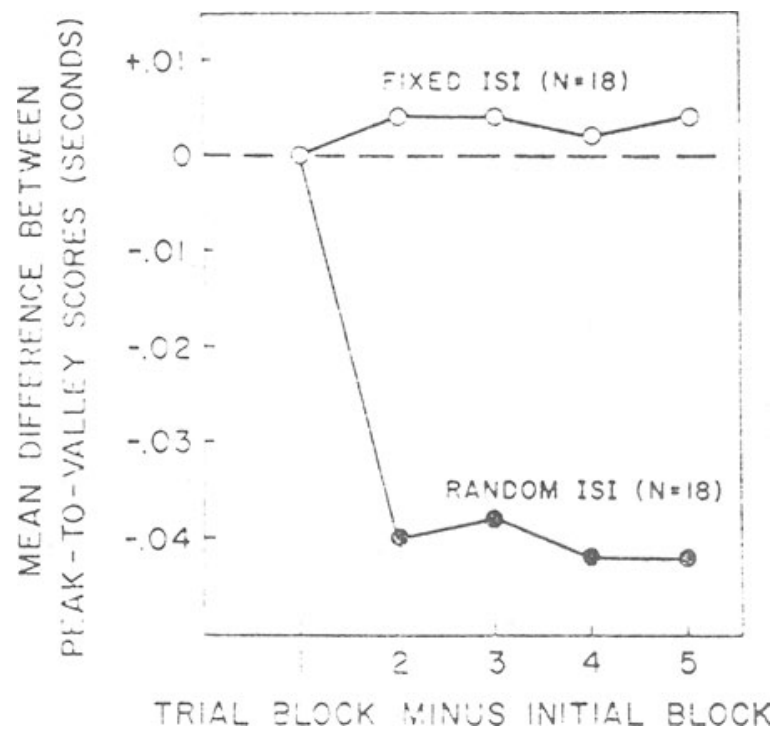

Fig. 1. Mean peak-to-valley scores for Ss in the combined FI and VI groups across five trial blocks.

component of the response was analyzed separately. Although these findings are consistent with assumptions derived from Geer's work, and they supnort the utility of the peak-to-valley score. thet are in distinct contradiction to Lang and Hnatiow" original findings with a 60 -ses FI. To be sure. there are many differences between their experiment and the present one. and future studies should address themselves to these differences. They used male Ss. we used predominantly female Ss. Ther used a 60 -sec interval. We used 30 . They used auditory stimulation. and we used tactile stimulation.

It is significant to note that. in the present study. the peak-to-ralley score appeared to be a useful and valid measure of the cardiai response, although the diphasic response it was designed to measure failed to materialize. This is not surprising. for the peak-to-valley score will yield a reliable positive score under any of the following conditions: 11 if the response is diphasic. (2) if the response is a monophasic. long-latency deceleration. and $(3)$ if the response is a monophasic. short-lateniy acceleration. In the first and second conditions. there would be little difference in score. for the decelerative component which appears more than five beats after stimulus presentation is subtracted from a prior faster heart rate. whether this faster rate was at base level or was accelerated from base level. In the third case. if the HR accelerates rapidly. and then returns to base level. the resuit is the same-a positive peak-to-valley score. Thus. it can be seen that the measure is remarkably robust. and is not dependent upon a diphasic response for its application. Yet. it appears that. in the present study. the peak-to-ralley score was operating most frequently as an index of a decelerative response.

\section{REFERENCES}

Geer. J. H. Measurement of the conditioned cardiac response. Journal of Comparative \& Physiological Psychology, 1964.57. $+26 \cdot 433$.

Lang. P. J. \& Hnatiow. M. Stimulus repetition and the heart rate response. Journal of Comparative \& Physiological Psychology. 1962. 55. $781-785$.

Opton. E.. Jr.. Rankin. X. O.. \& Lazarus. R. S. A simplified method of heart rate measurement. Psychophysiology. 1965. 2. $87-97$.

Sokolov. E. N. Higher nervous functions: The orienting reflex Annual Review of Physiology. 1963. 25. 545-580.

$$
\text { IRcorived for publication Ya! 14. 14-3.1 }
$$

